\title{
Process analytical technology for continuous manufacturing of solid-dosage forms
}

\author{
Margot Fonteyne ${ }^{\text {a. * }}$, Jurgen Vercruysse ${ }^{\mathrm{b}}$, Fien De Leersnyder ${ }^{\mathrm{a}}$, Bernd Van \\ Snick $^{\mathrm{b}}$, Chris Vervaet ${ }^{\mathrm{b}}$, Jean Paul Remon ${ }^{\mathrm{b}}$, Thomas De Beer ${ }^{\mathrm{a}}$ \\ ${ }^{a}$ Laboratory of Pharmaceutical Process Analytical Technology, Ottergemsesteenweg 460, Ghent University, \\ Ghent, Belgium \\ ${ }^{\mathrm{b}}$ Laboratory of Pharmaceutical Technology, Ghent University, Ghent, Belgium
}

\section{HIGHLIGHTS}

- Pharmaceutical production is switching from batch towards continuous processing

- Process Analytical Technology is indispensable for continuous manufacturing

- Implementation of Process Analytical Technology in continuous production

\begin{abstract}
Currently, pharmaceutical production is making the switch from batch processing towards continuous processing. The quality of intermediate and end products produced by batch processes is assured by off-line testing. It is obvious that off-line tests in analytical laboratories cancel out the advantages of continuous processing, so the critical quality attributes of continuously produced pharmaceuticals need to be monitored in real time. In 2004, the US Food and Drug Administration launched the process analytical technology (PAT) concept to stimulate the pharmaceutical industry to change from off-line to real-time quality testing. This review explores the implementation of PAT tools within continuous pharmaceutical processes (i.e., blending, spray drying, roller compaction, twin-screw granulation and compression), focusing on both opportunities and challenges.
\end{abstract}

Keywords:

Continuous blending

Continuous pharmaceutical manufacturing

Direct compression

Near infrared

Particle-size analysis

Process analytical technology

Raman

Roller compaction

Spray drying

Twin-screw granulation

Abbreviations: API, Active pharmaceutical ingredient; CQA, Critical quality attribute; EMEA, European Medicines Agency; FBRM, Focused beam reflectance measurement; FDA, Food and Drug Administration; HPLC, High-performance liquid chromatography; KF, Karl Fischer; LIF, Light-induced fluorescence; MBSD, Moving block standard deviation; NIR, Near infrared; PAT, Process analytical technology; PC, Principal component; PCA, Principal-component analysis; PLS, Partial least squares; QbD, Quality by Design; R\&D, Research and development; RSD, Residual standard deviation; UV, Ultraviolet

* Corresponding author. Tel.: +329264 8097.

E-mail address: Margot.Fonteyne@Ugent.be (M. Fonteyne) 


\section{Introduction}

Pharmaceutical manufacturers of conventional solid-dosage forms (i.e., capsules and tablets) are interested to switch from batch processing towards continuous processing [1]. Continuous processing is characterized by

(i) integration of all unit operations; and,

(ii) the "one in, one out" principle.

Starting materials are continuously fed into the process, whilst end products are continuously removed at the same speed [2]. Several processing steps, currently used in batch manufacturing, are continuous, such as:

(i) feeding;

(ii) milling;

(iii) roller compaction, which is a dry granulation technique;

(iv) compression, where a blend of the active pharmaceutical ingredient (API) and excipients is compressed into tablets; and,

(v) spray-drying, in which a liquid is atomized into drops and then dried in a hot air flow (Fig. 1).

Furthermore, in the past decade, several companies have developed integrated powder-totablet production lines [2]. It is obvious that, for continuous processing, real-time quality control is indispensable, so the need to invest in process analytical technology (PAT) is strengthened. With the Horizon 2020 framework program for research and innovation in mind, the European Federation for Pharmaceutical Sciences (EUFEPS) also highlighted the need for appropriate in-line measurements, in order to make possible lean continuous manufacturing [3]. This review aims at summarizing the status of the implementation and the suitability of PAT tools for continuous pharmaceutical manufacturing processes of conventional solid-dosage forms, focusing on opportunities and shortcomings. Saerens et al. [4] earlier provided an overview of PAT monitoring in continuous hot-melt extrusion.

The adoption of continuous manufacturing of solid-dosage forms brings several advantages, but also challenges (Table 1). The advantages have their impact in three fields:

(i) product development and quality;

(ii) costs; and,

(iii) footprint.

Continuous production equipment implies fewer scale-up issues, since the size of the production lot is defined by the factor "time", so the same equipment size can be used for development and pilot studies, clinical trials and full commercial production. Since timeintensive scale-up experiments are not needed, development time is significantly decreased and the product can be launched faster to the market. It is important to mention that, especially now with scarcely filled pipelines, shorter development time implies a longer monopoly for the company prior to patent expiry - a major economic advantage.

Comparison of the economics of batch and continuous pharmaceutical production was performed by Schaber et al. [5]. The capital investment of a continuous plant is lower since the equipment is smaller and intermediates do not need to be stored and transferred, so less floor space is required. In addition, the operating expenses decrease, because fewer operators are required for processing, transfer and storage. Evaluation and assurance of product quality no longer occurs via off-line testing, which also implies a significant cost reduction. Furthermore, the production of tablets in a continuous way will be more sustainable than via batch production, since the footprint reduces significantly [6].

One fair comment is that continuous manufacturing processes allow less flexibility. It is true that batch processes are very flexible. An almost infinite number of different process steps can be virtually linked, whereas a continuous process is more rigid, as the different unit 
operations are physically integrated into a specific process chain. However, recent advances were made in the development of readily "plug and play" continuous equipment, which allows flexible changes between direct compression and wet and dry granulation [7]. Continuous processes need to be robust with respect to changes in the product quality of raw materials and need to reach steady state quickly to avoid wastage of product.

The "batch"-concept is deep-seated within the pharmaceutical industry and small batches minimize financial losses in case a product needs to be recalled. A continuous process asks for a different tracking method (e.g., time stamps). Nevertheless, the biggest burden for the pharmaceutical industry to adopt continuous manufacturing seems to be the regulatory issues. If changes are made in the production of a product that is already licensed, these changes must be re-evaluated by the authorities. When a new production line needs to be evaluated and the product registration must be renewed, that is the right time to switch from batch to continuous processing. Continuously-produced nimesulide tablets (Severin by Chinion) have already been licensed and are available on the Mexican market.

Batch processes have mostly relied on off-line analysis for quality evaluation of intermediate and end products (i.e., quality by inspection). However, continuous processes should be evaluated in real time by means of at-line, on-line and in-line measurements, as described in the PAT guidance for industry, launched by the US Food and Drug Administration (FDA) [8]. Furthermore, in their "Pharmaceutical Development" guideline, the International Conference on Harmonization of Technical Requirements for Registration of Pharmaceuticals for Human Use (ICH) defines the Real Time Release Testing principle: "the quality of both intermediate and final products needs to be evaluated and ensured based on process data" [9]. These data can then be used for the construction of feedback and feedforward control loops. This means that, when a process is fully understood and the quality of the end-product can be assured at any time, a product can be released directly to the market after production.

\section{Implementing PAT tools in continuous pharmaceutical processes}

\subsection{Continuous material transfer between units}

At certain time-points during pharmaceutical processes the homogeneity of powder streams needs to be evaluated. The in-line measurement of powder streams is challenging, for several reasons:

(i) fouling of the measurement probe frequently occurs;

(ii) it is not always easy to define the actual sample size (e.g., the sampling volume of powder measured during the collection of a spectrum); and,

(iii) the location of the probe should be investigated, since the probe should not block nor influence the powder stream; at the same time, it should be placed so that the moving powder stream is measured, not, e.g., only powder that is sticking to the hopper wall (i.e., when channeling occurs).

Benedetti et al. [10] developed a specially designed, non-contact sampling interfacing device with sapphire glass for quantitative evaluation of the API concentration in a flowing powder stream by means of near-infrared (NIR) spectroscopy. Spectra collection happened through the sapphire window and no fouling of the window was reported. A partial least squares (PLS) calibration model was built, using manually blended samples, which were measured in a static way. These samples were not fully homogeneous, hence not representative of the powder stream, which was homogenously blended on an industrial scale. The authors solved this problem by averaging 10 calibration spectra of each calibration blend and then obtained a good PLS model. Another concern was that static measurements are not 
influenced by any interference from air diffusion, powder packing differences or flow velocity. The spectral variation did not seem to be affected by the flow rate, whereas differences in compaction level and particle-flow discontinuity could be removed by data pretreatment. The real-time measured API concentration showed a large standard deviation (around 6). This was overcome by averaging the model-predicted API concentration over one unit dose of product, decreasing the standard deviation to 3 and below, depending on the run being evaluated.

\subsection{Continuous blending}

So far, two techniques have been presented for the monitoring of continuous blending, namely NIR and light-induced fluorescence (LIF).

In 2010, Vanarase et al. [11] constructed an NIR-PLS model to determine the API concentration of flowing powder in-line. The spectra were collected from blends, passing under the NIR probe head on a chute at the outlet of a continuous blender. The calibration model was constructed using spectra of flowing powders. In a second paper [12], measurements were again conducted with the help of a chute, but, this time, a multi-point NIR system, equipped with five probes, was mounted above the chute. Multi-point systems have several advantages, such as instrument or process failure diagnostics (by comparing the spectra collected by different probes). Furthermore, one spectrometer can be used to monitor a whole continuous production process. In this study, the correlation between in-line (NIR) and off-line (UV) measurements was determined as well as the analytical method error of the respective methods, which was negligible for both techniques. A PLS-calibration model was constructed with spectra of static samples, and a PLS model was constructed, based on the spectra collected by the five different probes. The model consisted of five latent variables, because the use of different probes increased the complexity of the spectra. Another possibility to avoid this would have been to construct five separate models, one for each probe. In this paper [12], the calculations of the amount of spectra, which needed to be averaged in order to be comparable to one unit dose, were also explained extensively.

Whereas Vanarase et al. [12] prepared the calibration samples with a separate batch blender, Martínez et al. [13] produced the calibration samples for the construction of a PLS model directly with the continuous blender, which was equipped with two feeders. A PLS model for API quantification was constructed and the influence of changing process parameters was evaluated. When the powder-flow rate was decreased, the predicted API concentration also decreased by $20 \%$, whereas the HPLC reference method showed that the blend was within specification. Martínez et al. [13] suggested that a lower interaction between incident light and powder particles might cause this underestimation. However, the absolute prediction of the target concentration was not influenced by changing the rotation speed of the blender. Moreover, a lower rotation speed led to less fluctuation in the predictions of the API concentration and in the residual standard deviation (RSD), as the sample was presented more adequately to the NIR probe and the mixtures were more uniformly blended at lower rotation speeds. Martínez et al. [13] also applied principalcomponent analysis (PCA) to the spectra of runs with different process parameters. The PCA classified the spectra according to stirring rate (PC1) and powder-flow rate (PC2), indicating that NIR is sensitive to powder flow and powder density. The respective loadings of the principal components were complicated to interpret. Furthermore, the in-line collected spectra were used to determine the start-up, steady-state and shut-down phases of the continuous blending process. Calculations were performed via PCA, RSD and moving block standard deviation (MBSD), but no method was superior to any other for determination of the end of the start-up phase. 
An extensive study on the performance of both a continuous ZigZag blender and a double helical ribbon blender was conducted by Pernenkil [14]. Tests were performed by not only inline NIR spectroscopy, but also LIF. Kehlenbeck [15] summarized parts of his $\mathrm{PhD}$ dissertation [16], which described in-line concentration determination of continuously blended mixtures by means of NIR. Furthermore, he presented a device that can be mounted on a probe head and cleans the probe tip by means of compressed air during processing.

Although Raman spectroscopy has proved useful in monitoring blend homogeneity in batch processes $[17,18]$, no applications of Raman spectroscopy in continuous blending have been presented so far.

\subsection{Spray drying}

Particle-size distribution is a critical quality attribute (CQA) of spray-dried material, so the size of the microspheres was monitored by a laser-diffraction system [19]. The performance of the system was compared when used in-line, at-line and off-line. In-line measurements were performed between the spray dryer and the cyclone, whereas at-line measurements were conducted after the product had left the process stream. Off-line analysis was performed both by laser diffraction and light microscopy. During both in-line and at-line measurements a purge air flow was needed in order to prevent particles adhering to the lenses of the measurement system. Furthermore, extra purged air was used for a better dispersion of the particles during at-line measurements.

The four different measurements did not yield the same results: the median particle size was around $33 \%$ higher when the measurements were conducted in-line, compared to the results obtained via light microscopy. The results from the at-line and off-line laser diffraction were similar, but still slightly higher than the median particle-size values obtained via light microscopy. This phenomenon was caused by the abundance of a dispersion stage during in-line measurements, resulting in the measurement of more agglomerates instead of discrete particles. However, an in-line system measures product changes in real time, providing information regarding, e.g., intermittent process upsets and length of the start-up phase. Unfortunately, the in-line system seemed to be insensitive to small changes in particle size. Furthermore, the at-line set-up has the advantage that lenses can be cleaned without the need to stop the production process. Moreover, the same measurement equipment can be used after different processes, allowing greater flexibility and reducing the costs. Even though atline analysis method is destructive, the authors still preferred it.

\subsection{Roller compaction}

The first monitoring technique applied on roller compaction is acoustic emission, where the signal produced by compressed powder is recorded with a microphone and then transformed to a frequency spectrum [20-22]. Changes in acoustic emission bands could be noticed with various compression forces and when capping occurred. The in-line monitoring of roller compaction was also studied by a research group at Purdue University (USA), in several studies with NIR spectroscopy on roller-compacted ribbons. The CQAs of rollercompacted granules are the granule characteristics (e.g., moisture content, relative density, tensile strength, and particle-size distribution) and the content uniformity. To monitor these CQAs, there were three studies [23-25], in which NIR spectra from the mid-point of the ribbons as they exited the rolls were collected in-line.

In the first study, samples were produced under different process conditions and measured off-line to construct predictive models. These models, constructed with off-line data, were then used to monitor the continuously produced ribbons in real time. When ribbons were 
produced with higher compression forces, an increase in absorbance could be noted. Then, a model for the prediction of the mechanical strength of the ribbons, based on the slope of the best-fit line through the spectra was constructed (calculated by regression analysis). The model could also be used to predict the particle-size distribution of the compacts after milling [23].

In the second study [24], PLS models were constructed in order to predict the moisture content, relative density, tensile strength and Young's modulus of the ribbons. Although the model constructed off-line showed good agreement between the spectra and the values from reference methods, the model could not be transferred to an in-line setting. Large differences between the values obtained by means of reference techniques and the predictions from the PLS model could be noted, because the NIR spectra, used for the construction of the PLS model, were collected after $24 \mathrm{~h}$ of storage. The different degrees of elastic recovery between fresh and stored ribbons caused the discrepancy, according to the authors.

In their next study [25], the off-line spectra for model-construction were therefore collected from the ribbons directly after their production. Again, an NIR-based PLS model was constructed for the prediction of relative density, moisture content, tensile strength and Young's modulus. In this study, an API was also added to the ribbons, so the PLS model also predicted API concentration. This time, good agreement was found between the values predicted by the NIR method and values obtained via reference methods. Nevertheless, whereas the scatters on the predicted moisture content and API-concentration values were low, large scatters were found for the predictions of the other three characteristics. The authors explained that this was due to the phenomenon of powder by-pass during rolling compaction, whereby a small amount of powder is not compacted, and hence creates dust clouds. These powder clouds are also measured by the NIR probe, and, whereas the moisture content and API-concentration in the powder cloud is similar to that of the ribbon, this is not the case for relative density, tensile strength and Young's modulus. Consequently, extra scatters are caused for the latter properties.

These studies also showed that it is important to conduct the calibration experiments in similar circumstances to these in which the model will be applied afterwards. Later, predictive models for granule and ribbon properties were constructed, taking into account not only the NIR spectral slope, but also raw-material properties, operating parameters and roll gap [26].

The fact that dust and the rather low detection sensitivity might lead to inconsistent collection of in-line NIR spectra was also recognized by Feng et al. [27]. They determined the sources of variability in in-line collected NIR spectra during roller compaction (i.e., motion of the rollers) and designed a new in-line control kit. Using this kit, the above mentioned dust clouds reduced, so the light-stray effects also decreased. Furthermore, the position and the movement of the ribbons were strictly controlled after compaction, which reduced the fluctuations in light stray even more. Less relaxation and deformation of the ribbons occurred, also causing fewer disturbances to the NIR signal.

In 2012, a study monitoring ribbon density in real time aimed at implementing NIR spectroscopy to monitor physical changes in the ribbons, caused by variation in the operating conditions [28]. Not only pure spectral changes (baseline shifts) were evaluated for monitoring, but also PCA (qualitative analysis) and PLS (quantitative analysis) were used. The authors reported that PCA was the most suitable, least time-consuming method for density measurements.

NIR spectroscopy was also compared to microwave-resonance sensing for in-line monitoring of density and moisture content of roller compacts [29]. PLS models were constructed and, in both cases, microwave resonance proved to be more accurate than NIR. Root mean square errors were almost double for NIR compared to those for microwave- 
resonance models. The optimized microwave-resonance PLS model for density showed an RMSE of $0.034 \mathrm{~g} / \mathrm{mL}$ (evaluated range $0.675-1.216 \mathrm{~g} / \mathrm{mL}$ ) whereas the optimized RMSE for moisture determination was $0.065 \%$ (evaluated range $2.1-5.5 \%$ water). Both techniques have different penetration depths; where the penetration depth of NIR is a few millimeters, microwave-resonance sensors penetrate several centimeters into the material; hence the microwave signal is transmitted through the whole ribbon. Since there is a direct relation between microwave sensor measurements and the presented mass in the measurement field, an accurate model for the determination of ribbon density could be obtained. Furthermore, there is a large contrast between the dielectric properties of water and most excipients, as microwave resonance is very sensitive to water. Hence, microwave-resonance-content models are also more accurate than NIR models for moisture determination. In addition, no chemometric calculations are necessary to derive the relevant information from microwaveresonance data. However, microwave resonance does not provide chemical information of the sample, as does NIR.

A research group in Singapore performed similar work on ribbed flakes produced by roller compaction. Different PLS models, based on off-line NIR spectra were constructed for the prediction of API concentration, tensile strength, Young's modulus and relative density [30]. Calibration spectra were collected in both static and dynamic ways (with a conveyor belt). The advantage of collecting dynamic spectra is that the sample measured is larger. When evaluating the $\mathrm{R}^{2}$ of the performance of the models, it was superior using the spectra that were collected (i) dynamically, and (ii) at the underside of the conveyer belt, and (iii) when the first derivative of the spectra was used for model construction. A good correlation between the predicted value and the reference value was observed for all characteristics. The variations of the predicted tensile strength, Young's modulus and relative density were higher than the variations of the API concentration - again because samples were stored for three days prior to off-line investigation and were subject to relaxation and temperature effects. The researchers corrected for the powder by-pass dust cloud by vacuuming out the dust particles, hence preventing the probe from fouling. In a second study [31], the optimal probelens diameter and distance to the sample were determined.

\subsection{Twin-screw granulation}

The CQAs of wet granules are: solid states of API and excipients, granule-size distribution, shape of granules and moisture content.

The influence of process parameters upon the solid state of theophylline (anhydrous or monohydrate) after twin-screw granulation was monitored with NIR and Raman spectroscopy [32]. Both spectroscopic techniques, with the help of multivariate data analysis, were capable of detecting even small unexpected solid-state changes. Solid-state differentiation was more definite in the Raman spectra than in the NIR spectra. As spectra were collected in a static way, more investigations on probe implementation in wet granulation would be advantageous. In the same study, the granule-size distribution of the wet granules was investigated in a dynamic way, by means of a spatial filter velocimetry probe (Parsum). Although it was equipped with an air-cleaning system, fouling of the probe remained a problem.

The effect of formulation and process parameters upon granule-size distribution was also measured dynamically with a high-speed imaging camera (Eyecon). This photometric stereoimaging technique is equipped with LEDs in three colors and provides information regarding not only particle size, but also shape and surface, although not discussed in this study [33]. The size-determination measurements do not need prior calibration and the technique is completely non-invasive. Adequate sample presentation is challenging, since non-spherical 
particles will always be presented at their largest particle dimension when they are measured on a chute, so a free-falling stream was used. Furthermore, when the field of view is overfilled, this interferes with an adequate granule size measurement calculation. It is therefore important that fine and coarse particles are separated during sample presentation. Fouling might be a problem when working with small powders. The distance of the samples to the lens needs to be constant and adapted to the focal distance of the system. In this study, $d 10$ values and particle count were preferred for process monitoring over $d 50$ and $d 90$ values. The camera was sensitive to changes in granule size and count when the liquid:solid ratio was changed.

Twin-screw granulation was also used as the wet granulation technique in a full, continuous powder-to-tablet production line, which was recently developed (the ConsiGma25 system). The ConsiGma system comprises a twin-screw granulator, connected to a segmented fluid-bed dryer and a transfer module equipped with a mill. A tablet press can also be added to this system. Four studies of the implementation of PAT tools within the ConsiGma system have been reported, one focused on the continuous fluid-bed dryer.

Chablani et al. [34] mounted an NIR probe in the granule-transfer module, which is situated just after the fluid-bed dryer, hence evaluating the dried granules. Two PLS models were constructed where the NIR spectra were regressed against the moisture content of the granules determined via Karl Fischer (KF) titration and "loss on drying", respectively. KF titration resulted in the superior model. Only a small range of moisture contents was evaluated $(0.43-1.06 \%$ w/w, measured with KF). After the fluid-bed granulator, a continuous mill was installed and the particle-size distribution of milled granules was evaluated by focused beam reflectance measurement (FBRM) [35].

Fonteyne et al. [36] performed a Design of Experiments, varying the temperature of the granulator barrel, the powder-feed rate and the temperature of the drying air in the fluid-bed dryer. The granules obtained were then evaluated at-line by Raman and NIR spectroscopy and a photometric imaging technique (Flashsizer3D). The spectroscopic techniques gave insight into the changing solid state of the API when different process parameters were applied, whereas the Flashsizer determined the granule-size distribution and the roughness of the granules. This complementary physical and chemical information was then used to predict the CQAs of the granules, namely moisture content, bulk and tapped density and flowability. Three PLS models were successfully constructed. The spectroscopic data had the highest predictive capability for the moisture content, whereas the imaging data were mostly correlated with the flowability of the granules. The measurements were performed at-line, since fouling occurred when using the Flashsizer in-line. The development of an interfacing device that prevents the Flashsizer window from fouling is the next challenge.

The use of classical fluid-bed end-point-detection methods (i.e., humidity of the outlet drying air and product temperature) has been compared to the use of PAT tools (NIR and Raman spectroscopy) and a mass-balance-model approach [37]. Both the NIR and Raman spectroscopy probes were mounted in the continuous fluid-bed dryer and an NIR-based moisture-prediction model was constructed. As well as real-time monitoring of the residual moisture of the granules, the solid state of the API was also successfully monitored. For realtime end-point detection, the PAT approach was superior to both the classical end-point detection and the mass-balance models.

\subsection{Direct compression}

In 2009, the successful use of NIR spectroscopy in a tablet press for monitoring powder segregation was presented at the EMEA/EFPIA QbD Application Workshop [38]. Measurements were conducted in-line in the feed frame. Karande et al. [39] placed an NIR 
probe just after the tablet-ejection area and constructed a PLS model to calculate the concentration of the API and the excipients. This study exposed that it is important to use similar sampling methods and circumstances for the collection of both calibration spectra and real-time process spectra. The calibration spectra were therefore also collected in a dynamic way using the tableting machine equipped with blank discs instead of punches and dies. Furthermore, preprocessing techniques (standard normal variate correction and derivatives) were used to minimize effects caused by differences between preparation during calibration and production. The in-line NIR monitoring discovered segregation towards the end of the production process. The concentration of the API in the tablets decreased in the second half of the process. Whereas this was clearly picked up by the NIR method, no anomalies could be detected with the classical UV method.

Wahl et al. [40] implemented an NIR probe directly above the paddle wheel, and they also detected segregation towards the end of the process. Järvinen et al. [41] monitored not only the individual tablets on the tablet press but also the powder stream coming from a continuous mixer prior to tableting. Both calibration and test-run spectra were collected inline. This study proved that it is possible to perform a $100 \%$ identity check (i.e., each individual tablet is monitored). The goodness of the method was confirmed during test runs with differing API contents, tableting speeds and compaction forces.

NIR measurements were also performed in the feed frame of a tablet press [42]. The derivative intensity of the API band was plotted versus time, and the influence of mass-flow rate, potency ingress and paddle-wheel speed on the method performance was studied. Both at changing mass-flow rate and potency variability, the change in NIR signal could be correlated to the off-line measured tablet potency. However, when changing the paddle-wheel rotation speed, a faster increase of NIR signal than tablet potency could be detected. The reason for this discrepancy was not yet understood.

Singh et al. [43] presented a feedback-control system implemented in a tableting pilot plant. Next to the classical sensors, implemented in the machine, they also implemented a microNIR sensor, which was installed on a chute at the outlet of a continuous convective blender mixing the API with the excipients. The quality of the collected NIR spectra was first tested by PCA and the API composition was predicted by a PLS model. The API composition was then altered, in order to evaluate the performance of the feedback-control operation. This hybrid MPC-PID (model predictive control, proportional integral derivative) approach brought the API concentration to the set point most quickly so it performed better than the PID control scheme with which it was compared.

\section{Conclusion and future challenges}

Overall, a limited amount of studies regarding implementation of PAT in continuous pharmaceutical processes have been conducted. Although researchers have worked on different continuous processes, they came across similar challenges (Table 2), as follows.

(1) The importance of similarity between the measurement conditions when collecting calibration spectra compared to the in-process collection of spectra.

(2) There is a need for adequate interfacing of the tools. An interfacing device should make sure that the probe does not interfere with the process or the product stream. In other words: chutes, e.g., are usable in an R\&D environment but should be switched to contained devices in a production setting.

(3) Since pharmaceutical processing deals with powders, fouling of probes is a muchreported problem when implementing PAT probes. The first solutions are now on the market (e.g., the FBRM probe with scraper, Parsum with air purge, and Lighthouse Probe with window wash). Manufacturers could improve the usability of their products 
significantly by providing a solution against probe fouling. Another option to prevent fouling is to use probes that have a large focal distance (e.g., the Raman PhAT probe).

(4) From this review, it is clear that NIR spectroscopy is the most used PAT tool. Nevertheless, researchers should question which tool is the most appropriate for monitoring a certain CQA. Often, NIR spectroscopy is used because it is the most readily available technique, but other techniques might be superior.

(5) When aiming for real-time-release, the process should be not only monitored, but also steered. So far, no research has been presented with information derived from PAT tools being used for feedback and feedforward steering of the pharmaceutical process.

\section{References}

[1] K. Plumb, Continous processing in the pharmaceutical industry: changing the mind set. Chem. Eng. Res. Des. 83 (2005) 730-738.

[2] C. Vervaet, J. Vercruysse, J. Remon, T. De Beer, Continuous Processing of Pharmaceuticals, Taylor and Francis. New York, 2013, pp. 644.

[3] R. Gaspar, B. Aksu, A. Cuine, M. Danhof, M.J.M. Takac, H.H. Linden, A. Link, E.M. Muchitsch, C.G. Wilson, P. Öhrngren, L. Dencker, Towards a European Strategy for Medicines Research (2014-2020): The EUFEPS Position Paper on Horizon 2020, Eur. J. Pharm. Sci. 47 (2012) 979-987.

[4] L. Saerens, C. Vervaet, J.P. Remon, T. De Beer, J., Process monitoring and visualization solutions for hot-melt extrusion: A review. Pharm. Pharmacol. 66 (2014) 180-203.

[5] S.D. Schaber, D.I. Gerogiogis, R. Ramachandran, J.M.B. Evans, P.I. Barton, B.L. Trout, Economic analysis of integrated continuous and batch pharmaceutical manufacturing: a case study. Ind. Eng. Chem. Res. 50 (2011) 10083-10092.

[6] W. De Soete, J. Dewulf, P. Cappuyns, G. Van der Vorst, B. Heirman, W. Aelterman, K. Schoeters, H. Van Langenhove, Exergetic sustainability assessment of batch versus continuous wet granulation based pharmaceutical tablet manufacturing: a cohesive analysis at three different levels. Green Chem. 15 (2013) 3039-3048.

[7] P. Hurter, T. Hayden, D. Nadig, D. Emiabata-Smith, A. Paone, Implementing continuous manufacturing to streamline and accelerate drug development. AAPS Newsmagazine (2013) 15-19.

[8] FDA-Adminstration, Guidance for Industry - PAT - A Framework for Innovative Pharmaceutical Development, Manufacturing, and Quality Assurance. 2004.

[9] International Conference on Harmonisation of Technical Requirements for Registration of Pharmaceuticals for Human Use. Pharmaceutical Development Q8. 2009.

[10] C. Benedetti, N. Abatzoglou, J.S. Simard, L. McDermott, G. Leonarda, L. Cartilier, Cohesive, multicomponent, dense powder flow characterisation by NIR. Int. J. Pharm. 336 (2007) 292-301.

[11] A.U. Vanarase, M. Alcala, J.I.J. Rozo, F.J. Muzzio, R.J. Romanach, Real-time monitoring of drug concentration in a continuous powder mixing process using NMR spectroscopy. Chem. Eng. Sci. 65 (2010) 5728-5733.

[12] A.U. Vanarase, M. Jarvinen, J. Paaso, F.J. Muzzio, Development of a methodology to estimate error in the on-line measurements of blend uniformity in a continuous powder mixing process.

Powder Technol. 241 (2013) 263-271.

[13] L. Martinez, A. Peinado, L. Liesum, G. Betz, Use of near-inrared spectroscopy to quantify drug content on a continuous blending process: influence of mass flow and rotation speed variations. Eur. J. Pharm. Biopharm. 84 (2013) 606-615.

[14] L. Pernenkil, Continuous blending of dry pharmaceutical powders, Massachusetts Institute of Technology. 2008.

[15] V. Kehlenbeck, Use of Near Infrared Spectroscopy for In- and Off-Line Performance Determination of Continuous and Batch Powder Mixers: Opportunities \& Challenges.

Proc. Food Sci. 1 (2011) 2015-2022.

[16] V. Kehlenbeck, Continuous dynamic mixing of cohesive powders. Technische Universität München. München, 2006. 
[17] G.J. Vergote, T.R.M. De Beer, C. Vervaet, J.P. Remon, W.R.G. Baeyens, N. Diericx, F. Verpoort, In-line monitoring of a pharmaceutical blending process using FT-Raman spectroscopy. Eur. J. Pharm. Sci. 21 (2004) 479-485.

[18] T.R.M. De Beer, C. Bodson, B. Dejaegher, B. Walczak, P. Vercruysse, A. Burggraeve, A. Lemos, L. Delattre, Y.V. Heyden, J.P. Remon, C. Vervaete, W.R.G. Baeyens, Raman spectroscopy as a process analytical technology (PAT) tool for the in-line monitoring and understanding of a powder blending process. J. Pharm. Biomed. Anal. 48 (2008) 772-779.

[19] L.W. Chan, L.H. Tan, P.W.S. Heng, Process analytical technology: Application to particle sizing in spray drying. AAPS PharmsciTech 9 (2008) 259-266.

[20] A. Hakanen, E. Laine, H. Jalonen, K. Linsaari, J. Jokinen, Acousting-emission during powder compaction and its frequency spectral analysis. Drug Dev. Ind. Pharm. 19 (1993) 2539-2560.

[21] A. Hakanen, E. Laine, Acousting characterization of a crystalline cellulose powder during and after its compression. Drug Dev. Ind. Pharm. 21 (1995) 1573-1582.

[22] J. Salonen, K. Salmi, A. Hakanen, E. Laine, K. Linsaari, Monitoring the acoustic activity of a pharmaceutical powder during roller compaction. Internat. J. Pharm. 153 (1997) 257-261.

[23] A. Gupta, G.E. Peck, R.W. Miller, K.R. Morris, Nondestructive measurements of the compact strength and the particle-size distribution after milling of roller compacted powders by near-infrared spectroscopy. J. Pharm. Sci. 93 (2004) 1047-1053.

[24] A. Gupta, G.E. Peck, R.W. Miller, K.R. Morris, Influence of ambient moisture on the compaction behavior of microcrystalline cellulose powder undergoing uni-axial compression and roller-compaction: A comparative study using near-infrared spectroscopy. J. Pharm. Sci. 94 (2005) 2301-2313.

[25] A. Gupta, G.E. Peck, R.W. Miller, K.R. Morris, Real-time near-infrared monitoring of content uniformity, moisture content, compact density, tensile strength, and young's modulus of roller compacted powder blends. J. Pharm. Sci. 94 (2005) 1589-1597.

[26] J.L.P. Soh, N. Boersen, M.T. Carvajal, K.R. Morris, G.E. Peck, R. Pinal, Multivariate Data Analysis to Verify the Utility of Roll Gap and NIR Slope as Process Critical Control Parameters: Importance of Raw Material Attributes For Modeling Ribbon and Granule Properties in Roller Compaction. J. Pharm. Innov. 2 (2007) 106-124.

[27] T. Feng, F. Wang, R. Pinal, C. Wassgren, M.T. Carvajal, Investigation of the Variability of NIR In-line Monitoring of Roller Compaction Process by Using Fast Fourier Transform (FFT) Analysis.

AAPS PharmSciTech 9 (2008) 419-424.

[28] D. Acevedo, A. Muliadi, A. Giridhar, J.D. Litster, R.J. Romanach, Evaluation of three approaches for real-time monitoring of roller compaction with near infrared soectroscopy. AAPS PharmSciTech 13 (2012) 1005-1012.

[29] J. Austin, A. Gupta, R. McDonnell, G.V. Reklaitis, M.T. Harris, The use of near-infrared and microwave resonance sensing to monitor a continuous roller compaction process. J. Pharm. Sci. 102 (2013) 1895-1904.

[30] A.K. Samanta, A.D. Karande, K.Y. Ng, P.W.S. Heng, Application of near-infrared spectroscopy in real-time monitoring of product attributes of ribbed roller compacted flakes. AAPS PharmsciTech 14 (2013) 86-100.

[31] P.V. Quyet, A.K. Samanta, C.V. Liew, L.W. Chan, P.W.S. Heng, A prediction model for monitoring of ribbed roller compacted ribbons. J. Pharm. Sci. 102 (2013) 2667-2678.

[32] M. Fonteyne, J. Vercruysse, D.C. Díaz, D. Gildemyn, C. Vervaet, J.P. Remon, T.D. Beer, Real-time assessment of critical quality attributes of a continuousgranulation process. Pharm. Dev. Technol. 18 (2013) 85-97.

[33] A.S. El Hagrasy, P. Cruise, I. Jones, J.D. Litster, In-line size monitoring of a twin screw granulation process using high-speed imaging. J. Pharm. Innov. 8 (2013) 90-98.

[34] L. Chablani, M.K Taylor, A. Mehrotra, P. Rameas, W.C. Stagner, Inline Real-Time NearInfrared Granule Moisture Measurements of a Continuous Granulation-Drying-Milling Process, AAPS PharmsciTech 12 (2011) 1050-1055.

[35] V. Kumar, M.K. Taylor, A. Mehrota, W.C. Stagner, Real-time particle size analysis using focused beam reflectance measurement as a process analytical technology tool for a continuous granulation-drying-milling process. AAPS Pharmscitech 14 (2013) 523-530. 
[36] M. Fonteyne, S. Soares, J. Vercruysse, E. Peeters, A. Burggraeve, C. Vervaet, J.P. Remon, N. Sandler, T. De Beer, Prediction of quality attributes of continuously produced granules using complementary PAT tools. Eur. J. Pharm. Biopharm. 82 (2012) 429-436.

[37] M. Fonteyne, D. Gildemyn, E. Peeters, S. Mortier, J. Vercruysse, K.V. Gernaey, C. Vervaet, J.P. Remon, I. Nopens, T. De Beer, Moisture and drug solid-state monitoring during a continuous drying process using empirical and mass balance models. Eur. J. Pharm. Biopharm. 87 (2014) 616628.

[38] M. Diller, J. Kerridge, Feedback EMEA/Industry Discussion Eli Lilly \& Co Ltd Case study: Use of in-line near-infrared spectroscopy to monitor segregation of a pharmaceutical powder blend in a tablet press. London, 2009.

[39] A.D. Karande, P.W.S. Heng, C.V. Liew, In-line quantification of micronized drug and excipients in tablets by near infrared (NIR) spectroscopy: Real time monitoring of tableting process. Int. J. Pharm. 396 (2010) 63-74.

[40] P.R. Wahl, G. Fruhmann, S. Sacher, G. Straka, S. Sowinski, J.G. Khinast, PAT for tableting: inline monitoring of API and excipients via NIR spectroscopy. Eur. J. Pharm. Biopharm. 87 (2014) 271-278.

[41] K. Järvinen, W. Hoehe, M. Järvinen, S. Poutiainen, M. Juuti, S. Borchert, In-line monitoring of the drug content of powder mixtures and tablets by near-infrared spectroscopy during the continuous direct compression tableting process. Järvinen KEur. J. Pharm. Sci. 48 (2013) 680-688.

[42] H.W. Ward, D.O. Blackwood, M. Polizzi, H. Clarke, Monitoring blend potency in a tablet press feed frame using near infrared spectroscopy. J. Pharm. Biomed. Anal. 80 (2013) 18-23.

[43] R. Singh, A. Sahay, K.M. Karry, F. Muzzio, M. Ierapetritou, R. Ramachandran, Implementation of a hybrid MPC-PID control strategy using PAT tools into a direct compaction continuous pharmaceutical tablet manufacturing pilot-plant. Int. J. Pharm. 473 (2014) 38-54.

\section{Caption}

Fig. 1. Industrial processes most used for the production of pharmaceutical solid-dosage forms. 
Figure 1

Fig. 1

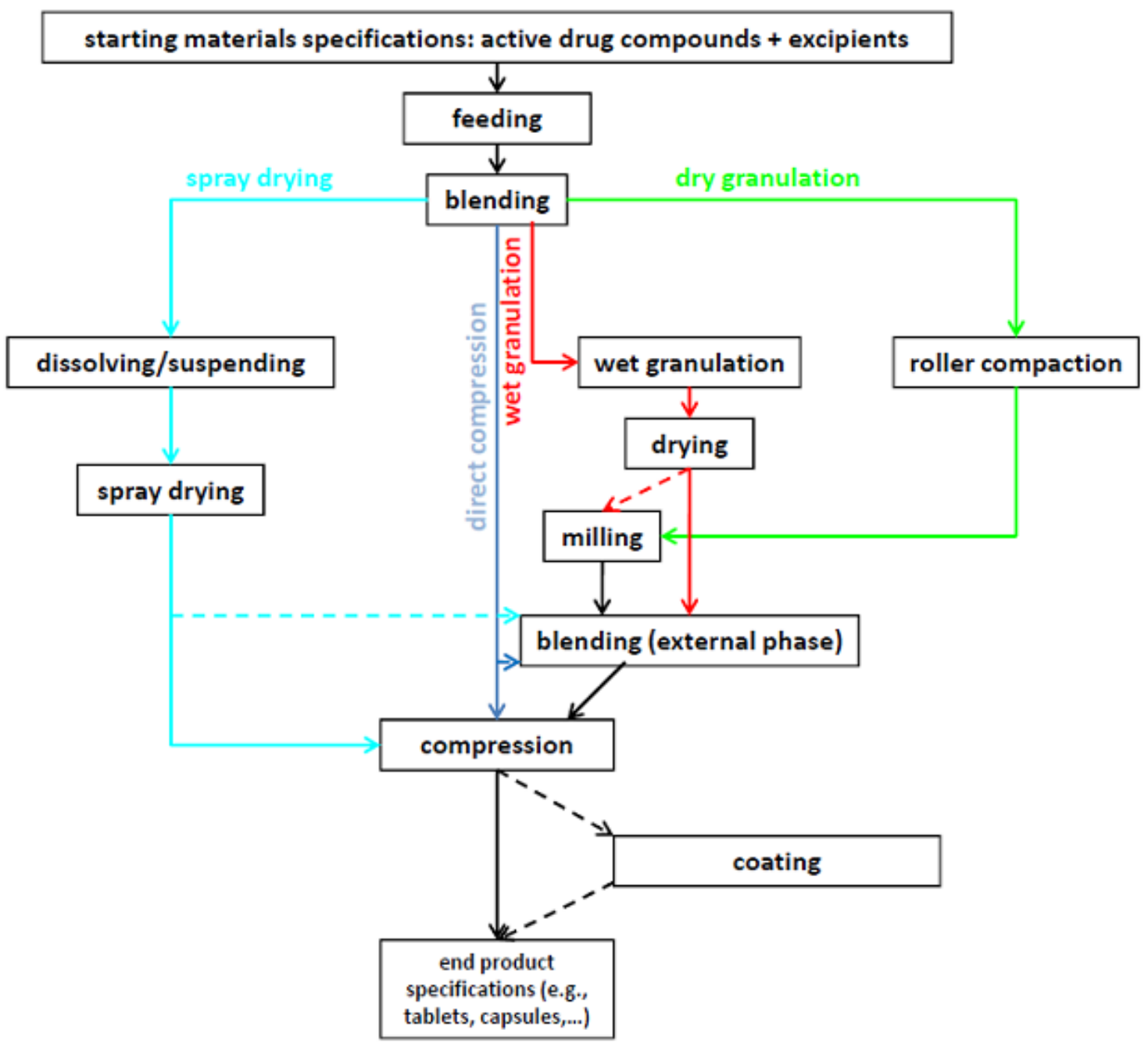


Table 1.

Advantages and challenges for the adoption of continuous processing in the pharmaceutical industry.

\begin{tabular}{|c|c|}
\hline Advantages & Challenges \\
\hline No scale-up issues & Not appropriate for small product loads \\
\hline Ease of automation & Less flexible regarding successive process steps \\
\hline Production of desired product amount & Need for fast steady state \\
\hline Better product quality assurance & Need for robust processes \\
\hline Shorter product development time & No obvious batch definition \\
\hline Shorter time-to-market & Production changes for already licensed products \\
\hline Just-in-time-production & Regulatory uncertainty \\
\hline Reduced capital investment & $\begin{array}{l}\text { New mind-set needed for quality assurance } \\
\text { (based on continuous in-process measurements) }\end{array}$ \\
\hline \multicolumn{2}{|l|}{ Reduction of labor costs } \\
\hline \multicolumn{2}{|l|}{ No transfer of intermediate products } \\
\hline \multicolumn{2}{|l|}{ No storage of intermediate products } \\
\hline \multicolumn{2}{|l|}{ Less floor space required } \\
\hline \multicolumn{2}{|l|}{ Less energy consumption } \\
\hline Less waste & \\
\hline
\end{tabular}


Table 2.

Literature overview on implementation of PAT tools in continuous pharmaceutical manufacturing

\begin{tabular}{|c|c|c|c|}
\hline Evaluated CQA & PAT tool & Interfacing & Challenges/shortcomings/problems \\
\hline \multicolumn{4}{|c|}{ Continuous powder } \\
\hline$\% A P I$ & NIR & $\begin{array}{l}\text { Through sapphire } \\
\text { window }\end{array}$ & $\begin{array}{l}\text { * Bench scale test set-up differs from } \\
\text { production scale powder hopper } \\
{ }^{*} \text { Averaging was necessary for both } \\
\text { calibration and prediction samples }\end{array}$ \\
\hline
\end{tabular}

Ref.

* Averaging was necessary for both

calibration and prediction samples

\section{Continuous blending}

\begin{tabular}{lllll} 
\%API & NIR & $\begin{array}{l}\text { Probe above the } \\
\text { powder, which flows } \\
\text { on a chute }\end{array}$ & $\begin{array}{l}\text { * Narrower concentration range needed to } \\
\text { be used in order to improve the prediction } \\
\text { of low concentration }\end{array}$ & [11] \\
\hline \%API & Multipoint & $\begin{array}{l}\text { Probe above the } \\
\text { powder, which flows } \\
\text { on a chute }\end{array}$ & $\begin{array}{l}\text { * Probe-tip fouling } \\
\text { * One model developed for the five probes } \\
\text { together, which resulted in additional } \\
\text { variance in the spectra }\end{array}$ & [12] \\
\hline NAPI & $\begin{array}{l}\text { Probe measuring at } \\
\text { the outlet of the } \\
\text { continuous blender }\end{array}$ & $\begin{array}{l}* \text { RSD varies with bulk variations of the } \\
\text { powder bed } \\
\text { * Mass-flow changes influenced the PLS } \\
\text { predictions }\end{array}$ & [13] \\
\hline
\end{tabular}




\section{Spray drying}

$\begin{array}{llll}\text { Particle size } & \text { Laser } & \text { Both in-line and at- } & * \text { Agglomerates were not differentiated } \\ \text { distribution } & \text { diffraction } & \text { line } & \text { from microspheres when measuring in-line } \\ & \text { (Insitec) } & & \begin{array}{l}* \text { Window fouling during in-line } \\ \text { measurements }\end{array}\end{array}$
measurements

\section{Roller compaction}

\begin{tabular}{|c|c|c|c|c|}
\hline Compression & $\begin{array}{l}\text { Acoustic } \\
\text { emission }\end{array}$ & $\begin{array}{l}\text { Microphone } 10 \mathrm{~cm} \\
\text { away from the } \\
\text { powder }\end{array}$ & $\begin{array}{l}* \mathrm{~S} / \mathrm{N} \text { is not optimal } \\
\text { *Peak overlapping makes quantitative } \\
\text { analysis difficult } \\
* \text { Harmonics of machine frequencies overlap } \\
\text { with interesting information }\end{array}$ & [20] \\
\hline Capping & $\begin{array}{l}\text { Acoustic } \\
\text { emission }\end{array}$ & $\begin{array}{l}\text { Microphone, isolated } \\
\text { from surrounding } \\
\text { structures }\end{array}$ & Similar & $\begin{array}{l}\text { [21]C: \Users\fonteynm\Documents\review\table.xlsx } \\
\text { - RANGE!_ENREF_19 }\end{array}$ \\
\hline Breaking force & NIR & $\begin{array}{l}\text { Real-time } \\
\text { measurements }\end{array}$ & / & [23] \\
\hline
\end{tabular}


Particle size after

milling

\begin{tabular}{|c|c|c|c|c|}
\hline Relative density & NIR & $\begin{array}{l}\text { Non-contact } \\
\text { measurements, focus } \\
\text { on mid-point of the } \\
\text { ribbons }\end{array}$ & $\begin{array}{l}\text { * Large differences between in-line } \\
\text { predictions and off-line measured values } \\
\text { * Variation due to non-ideal measurement } \\
\text { conditions }\end{array}$ & {$[24]$} \\
\hline \multicolumn{5}{|l|}{ Moisture content } \\
\hline \multicolumn{5}{|l|}{ Tensile strength } \\
\hline \multicolumn{5}{|l|}{ Young's modulus } \\
\hline$\% A P I$ & NIR & $\begin{array}{l}\text { Non-contact } \\
\text { measurements, focus } \\
\text { on mid-point of the } \\
\text { ribbons }\end{array}$ & $\begin{array}{l}\text { * Powder by-pass created dust clouds, } \\
\text { which confounded the relative density, } \\
\text { tensile strength and young's modulus } \\
\text { prediction }\end{array}$ & [25] \\
\hline \multicolumn{5}{|l|}{ Relative density } \\
\hline \multicolumn{5}{|l|}{ Moisture content } \\
\hline \multicolumn{5}{|l|}{ Tensile strength } \\
\hline \multicolumn{5}{|l|}{ Young's modulus } \\
\hline $\begin{array}{l}\text { Granule tablet } \\
\text { tensile strength }\end{array}$ & NIR & $\begin{array}{l}\text { Real-time } \\
\text { measurements of the } \\
\text { unloaded ribbons }\end{array}$ & / & $\begin{array}{l}\text { [26]C:\Users\fonteynm\Documents\review\table.xlsx } \\
\text { - RANGE!_ENREF_24 }\end{array}$ \\
\hline \multicolumn{5}{|l|}{$\begin{array}{l}\text { Granule mean } \\
\text { particle size } \\
\text { Ribbon density }\end{array}$} \\
\hline Ribbon density & NIR & $\begin{array}{l}\text { Real-time non- } \\
\text { contact } \\
\text { measurements, } \\
\text { probe head situated } \\
\text { above the ribbons }\end{array}$ & $\begin{array}{l}\text { * Difficult to find a good reference method to develop PLS } \\
\text { models predicting density. The sample area measured by the } \\
\text { reference technique is unequal to the area measured by NIR. } \\
\text { This causes an offset in the predictions }\end{array}$ & {$[28]$} \\
\hline
\end{tabular}




\begin{tabular}{|c|c|c|c|c|}
\hline \multirow[t]{2}{*}{ Ribbon density } & \multirow[t]{2}{*}{$\begin{array}{l}\text { NIR and } \\
\text { microwave } \\
\text { resonance } \\
\text { sensing }\end{array}$} & \multirow{2}{*}{$\begin{array}{l}\text { NIR: non-contact } \\
\text { measurements, } \\
\text { probe head situated } \\
\text { above the ribbons } \\
\text { RS: in-line with the } \\
\text { produced ribbon }\end{array}$} & \multirow{2}{*}{\multicolumn{2}{|c|}{$\begin{array}{l}\text { *NIR needs chemometrics to predict moisture and } \\
\text { ribbon density } \\
{ }^{*} \text { NIR has a small penetration depth * microwave } \\
\text { resonance sensing does not provide chemical } \\
\text { information }\end{array}$}} \\
\hline & & & & \\
\hline$\% A P I$ & NIR & $\begin{array}{l}\text { Use of rectangular } \\
\text { channel, creating a } \\
\text { constant gap } \\
\text { between probe head } \\
\text { and flakes }\end{array}$ & $\begin{array}{l}\text { * Important to keep the distance between probe } \\
\text { and flake constant } \\
\text { * Different models, predicting physical } \\
\text { characteristics needed to be constructed for } \\
\text { each used formulation }\end{array}$ & [30] \\
\hline \multicolumn{5}{|l|}{ Relative density } \\
\hline \multicolumn{5}{|l|}{ Tensile strength } \\
\hline Young's modulus & & & & \\
\hline
\end{tabular}

\section{Twin screw \\ granulation}

\begin{tabular}{lll} 
Solid state of the & $\begin{array}{l}\text { NIR, Raman } \\
\text { and spatial } \\
\text { filter } \\
\text { velocimetry }\end{array}$ & $\begin{array}{l}\text { At-line static } \\
\text { measurements, using } \\
\text { a cuvette }\end{array}$ \\
Granule size (d50) & $\begin{array}{l}\text { Spatial filter } \\
\text { velocimetry }\end{array}$ & $\begin{array}{l}\text { In-line, dynamic } \\
\text { measurements under } \\
\text { granulator outlet }\end{array}$ \\
\hline
\end{tabular}

SFV probe fouling

* Spectra are collected statically instead of in the product stream 


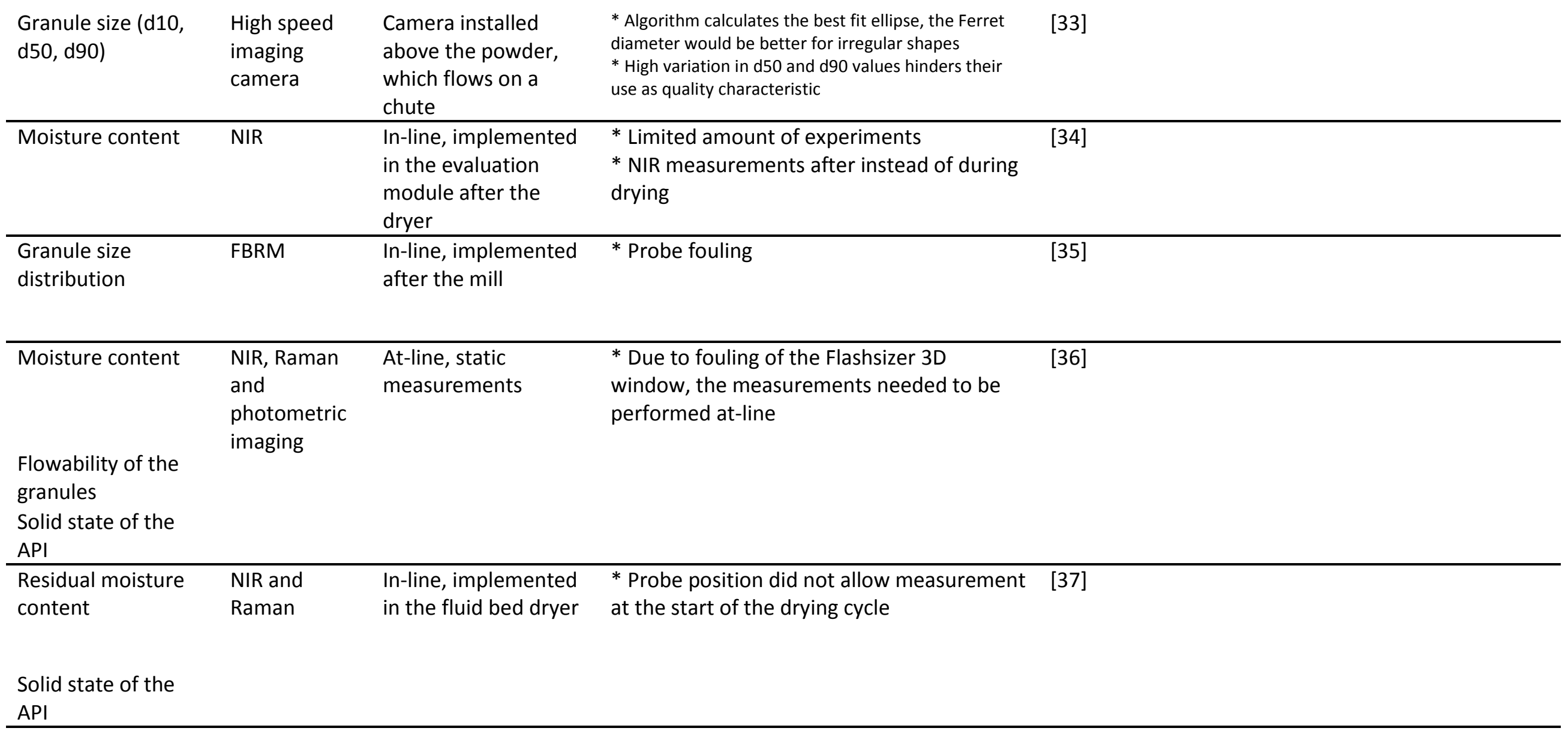


In-line, adjacent to the tablet ejection

area

NIR

$\% \mathrm{API}$ and
excipients

$\% A P I$

NIR

In-line in the tablet
In-line, in the feed

frame, directly above

the paddle wheel

press, measuring

each individual tablet
* Calibration spectra needed to be collected under the same conditions as the in-process data

* Method validation according to ICH Q2, which is not optimal for spectral data

* Lack of 'sample volume' definition and calculating the number of measured 'tablets' is challenging

* Due to the large amount of data, only each

20th spectrum was taken into account

Through a Plexi-glass

* NIR predictions were influenced by the

observation window paddle wheel rotational speed

in the feed frame
[39]

[40]

[41]
42]

\begin{tabular}{lll}
\hline \%API NIR & Through a Plexi-gl \\
& observation window \\
& in the feed frame
\end{tabular}

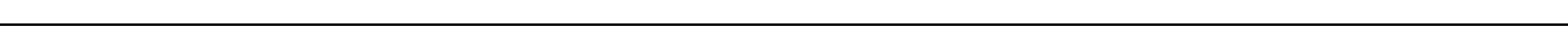


